This item was submitted to Loughborough's Research Repository by the author.

Items in Figshare are protected by copyright, with all rights reserved, unless otherwise indicated.

\title{
Affecting qualitative health psychology
}

PLEASE CITE THE PUBLISHED VERSION

http://dx.doi.org/10.1080/17437199.2010.544637

PUBLISHER

(C) Routledge (Taylor \& Francis)

VERSION

AM (Accepted Manuscript)

LICENCE

CC BY-NC-ND 4.0

REPOSITORY RECORD

Cromby, John. 2019. "Affecting Qualitative Health Psychology". figshare. https://hdl.handle.net/2134/11070. 
This item was submitted to Loughborough's Institutional Repository (https://dspace.lboro.ac.uk/) by the author and is made available under the following Creative Commons Licence conditions.

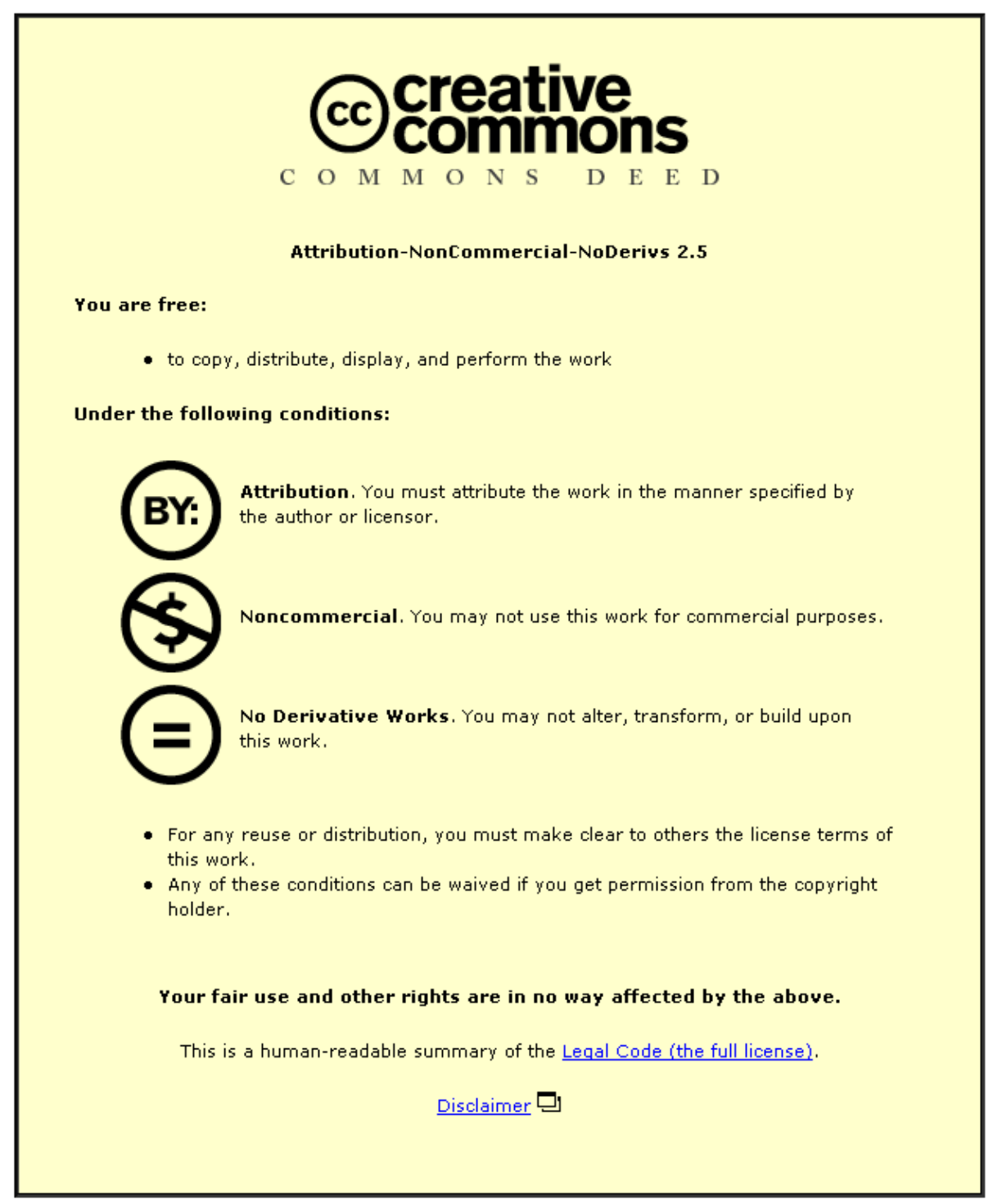

For the full text of this licence, please go to: http://creativecommons.org/licenses/by-nc-nd/2.5/ 
Affecting Qualitative Health Psychology

John Cromby

Health Psychology Review 5,1: 79-96 (2011)

Numbers in square brackets [p.xx] refer to page numbers in the published version.

Psychology Division, SSEHS

Loughborough University

Loughborough LE11 3UT, England UK

Email: J.Cromby@1boro.ac.uk 


\title{
[p.79] Affecting Qualitative Health Psychology
}

\begin{abstract}
The 'affective turn' is a contemporary movement within the humanities, social science and psychology to investigate affect, emotion and feeling as hybrid phenomena jointly constituted from both biological and social influences. Health and illness are themselves jointly constituted in this way, and many of the topics, concerns and methods of health psychology are strongly permeated by affective phenomena. Qualitative research in health psychology might therefore benefit by engaging with this work. This paper describes some features of the affective turn, and suggests theories, terminology and methods that might be useful.
\end{abstract}

\section{Introduction}

Currently, the human and social sciences are witnessing a renewed and growing interest in the phenomena indexed by the terms affect, emotion and feeling, and this is occurring to such an extent that many are saying that enquiry is undergoing an 'affective turn' (e.g. Athanasiou, Hantzaroula, \& Yannakopoulos, 2008; Clough \& Halley, 2007). Because they engage directly with important categories of experience these developments are relevant to psychology in general, and - since they also embrace aspects of embodiment - to health psychology in particular. Psychology has a sorry history with the body, tending either to ignore it (cognitive and social psychologies) or treat it as exclusively foundational (biological and neuro-psychologies). The affective turn may provide health psychologists with ways of thinking and researching that sidestep this unpalatable forced choice, allowing them to jointly explore aspects of social and bodily influences upon health and illness. Accordingly, in this paper I will sketch some of the contours of this turn to affect and summarise its relevance for health psychology. I will then describe some of the theoretical, terminological and methodological resources that qualitative health psychological research into affective phenomena might deploy.

\section{The Affective Turn}

Scholarship within the affective turn is not homogenous: it is distributed across many disciplines, engages with a range of substantive phenomena, and deploys evidence and concepts from sources including philosophy, psychoanalysis, psychology, neuroscience and emotion studies. But within this heterogeneity there is nevertheless [p.80] a deeper 
cohesion: a common understanding of affective phenomena as thoroughly hybrid and co-constituted. Affect, emotion and feeling are being treated neither as wholly biological nor as simple manifestations of language and the social realm. They are instead conceptualised, in various ways, as phenomena constituted jointly from social influence and biological capacity, and so necessarily hybrid in content, form and process. Whilst their occurrence is enabled by, and gains some of its character from, biology, it is simultaneously both interpellated ('called out') and co-constituted by influences operating through social relations, language and social practice.

Historically, analyses of the affective realm are not new; what is currently distinctive is the co-occurring acceleration of interest across disciplines including geography, literature, anthropology, social theory, criminology, sociology, psychology. Whilst not all of the scholars discussed here would explicitly describe themselves as participating in this emergent movement, all are distinctive both for their emphasis upon the affective and for neither reducing it to biology nor simply treating it as epiphenomenal to sociality. Indeed, there is a clear sense in which the affective turn both follows from and extends the linguistic turn that has characterised much qualitative research in health psychology (and elsewhere) in recent years (Greco \& Stenner, 2008). Rather than marking a break with or dismissal of the linguistic turn, the turn to affect is in many ways a continuation of it, because it is similarly characterised by a striving to better grasp the complexities of experience by not treating our 'inner' lives as a pure, unsullied, transcendent realm. Like the linguistic turn that preceded it, scholarship within the affective turn treats experience as something to be explained, rather than as explanation (Middleton \& Brown, 2005; Stephenson \& Papadopoulos, 2007); it understands subjectivity as emergent from and immanent within the flows of language and embodied social practice (Blackman, Cromby, Hook, Papadopoulos, \& Walkerdine, 2008), rather than treating it as pure origin and source.

Reflecting both its substantive diversity and the ways in which it permeates multiple disciplines, scholarship associated with the affective turn is heterogeneous and dispersed: for example, there have recently been journal special issues dealing with affect in disciplines including literature (Athanasiou et al., 2008), social theory and cultural studies (Blackman \& Venn, 2010) and psychology (Blackman \& Cromby, 2007). Within these writings, however, common tropes (bodies, hybridity, co-constitution, circulation, flow, 
contagion, suffusion, attunement) and related points of reference frequently recur. One source is Sedgewick (2003), whose psychologically-informed analyses include discussion of various emotions, most prominently shame; another is Brennan (2004), whose psychoanalytic account of affect transmission is supplemented with a materialist explanation grounded in the (putative) activity of human pheromones. However, not all accounts are psychological or psychoanalytic: some are informed by affective neuroscience (e.g. Damasio, 1999; Panksepp, 1998) or Deleuzian philosophy (Massumi, 1995; Thrift, 2007). Some affective research has an applied focus: in criminology, for example, there have been studies of the passions and sensuous pleasures of offending, using ethnography to explore how the marginalised reclaim space and mark identity through practices such as graffiti (Ferrell, 2003). Additionally, in presenting their work scholars in the affective turn sometimes adopt distinctive strategies: for example, Clough (2010) - another author very widely cited - provides an analysis of trauma that uses [p.81] photographs and poetry to evoke in her readers something of the affects she wishes to implicate.

The affective turn is of immediate, far-reaching relevance to health psychology because it attempts to include within analysis ways of experiencing, knowing and relating that are enabled by our character as embodied creatures, as well as - simultaneously with - our character as speaking beings. Health psychology is centrally defined by its relation to bodily experience, such that health and illness are sensible only as aspects of what it is to be embodied. There is also a deeper parallel with the affective turn because health and illness are themselves hybrid, co-constituted phenomena (Lyons \& Chamberlain, 2006). There is a stark affective dimension to our responses to illness and mortality, within which both our own experiences and those of our loved ones come to figure in ways that are inescapably and often profoundly emotional. Indeed, affectivity so thoroughly permeates health psychology that emotion has been proposed as central to our understandings of the body, health and illness (Scheper-Hughes \& Lock, 1987).

For example, the embodied feelings associated with symptoms are defining features of both illness and health, and their occurrence and recognition are thoroughly bound up with other feelings, categorised as affective or emotional (Costa \& McCrae, 1987; Watson \& Pennebaker, 1989). Bendelow's (2009) extended discussion particularly links emotion to medically unexplained symptoms, and to experiences characterised (reductively - 
Newton, 2003) as 'stress'. Similarly, studies of the difficulties, dilemmas and practices of medical professionals breaking bad news to patients display a constant concern with emotionality (Ptacek \& Eberhardt, 1996). There is also a profoundly affective dimension to problems of (so-called) psychopathology, with various recent analyses foregrounding the interplay of emotion and feeling as constitutive influences within the experiences associated with psychiatric diagnoses of eating disorders, depression, anxiety disorder and paranoid schizophrenia (Cromby, 2004; Cromby \& Harper, 2009; Meyer, Waller, \& Waters, 1998). Since emotions and feelings are thoroughly bound up with moral reasoning (Haidt, 2003) affective research also has potential to illuminate studies of medical ethics and decision making. Health psychology frequently addresses the implications and health consequences of everyday activities and behaviours, and interventions frequently enrol lifestyle advice (e.g. Jarvis \& Wardle, 2006; Lynch, Kaplan, \& Salonen, 1997; Nutbeam, 2000); and everyday life is thoroughly permeated by emotions and feelings (Scherer, Wranik, Sangsue, Tran, \& Scherer, 2004). Discussions of concordance with treatment similarly implicate both emotions and feelings: physiotherapeutic regimes frequently interpellate feelings of boredom and fatigue, whilst pharmaceutical regimes may evoke unpleasant feelings associated with the undesired effects of medication; additionally, many interventions enrol emotional responses powerfully constitutive of new and perhaps highly visible subject positions as disabled or ill (Hagger \& Orbell, 2006). Studies of the affective may also illuminate aspects of complementary and alternative medicine, which are often said to provide feelings of control (Boon et al., 2000), emotional support (Paltiel et al., 2001) and wellbeing (Sointu, 2006). Finally, of course, it is well-established that emotionality is closely bound up with both the experience and the management of pain (Bullington, 2009; Rhudy, Williams, McCabe, Rambo, \& Russell, 2006), and pain - itself a feeling - is a prominent component of many experiences of illness.[p.82]

In such ways, the terrain of health psychology is consistently suffused by various kinds of emotions and feelings; their investigation might therefore yield benefits. Efforts to do so will nevertheless encounter difficulties, the first of which are likely to be definitional. The diversity of scholarship within the affective turn is such that there are multiple definitions of even the basic terms affect, emotion and feeling. The three terms are frequently used all-but interchangeably, but alternately are also mobilised in ways that signal ontological differences and/or theoretical allegiances; this confusion is then frequently magnified by 
disciplinary preferences and traditions (6, Squire, Treacher, \& Radstone, 2007). Affect in Deleuzian philosophy is an intensity that flows within and between organisms, a force for becoming (the constant process of change that characterises life itself); affect is thus not so much something personally experienced as something pre-personal that constitutes experience. Alternately, in many variants of psychoanalysis affect refers to primary process activity that occurs outwith consciousness and can only ever (if at all) be known within it indirectly. However in neuroscience, many areas of psychology, and sometimes in psychoanalysis, too, affect is used all-but interchangeably with emotion. Psychology also frequently uses feeling as a synonym for both affect and emotion, although in common with other disciplines it frequently reserves this term to index phenomenological experiences. Indeed, whilst feeling is often used to index experiences of affect or emotion, even here there is variation: Damasio (1999) for example, distinguishes between 'feeling' as a neural and physiological state of the body-brain system, and 'a state of feeling made conscious' as an experience.

These are longstanding, widely-recognised problems: the difficulty of defining emotion has been much discussed (Griffiths, 1998) and some emotion scholars bemoan the lack of universally agreed definitions and taxonomies (J. Turner, 2000). Others suggest this is an inevitable consequence of the powerful cultural binding of emotion, implying that the hybrid, co-constituted character of affective phenomena inevitably means that a stable definition and universal taxonomy are unlikely ever to be achieved (Ratner, 2000). Blackman \& Venn (2010) propose that, rather than become distracted by definitions we should adopt a "more cautious" approach and consider what different conceptualisations of the affective might afford or do. This suggestion is appropriate to a moment when affect studies are still crystallising as a distinctive sphere of interest, although of course it is precisely because of their differential affordances and consequences that definitions will ultimately come to matter. Although health psychologists will need to adopt sensible definitions of affect, emotion and feeling in order to warrant empirical investigations, there is - for the moment, at least - space to choose which to invoke.

Whilst definitional problems are relevant to all empirical research, qualitative investigations of embodied, affective phenomena encounter a further difficulty because in practice most qualitative analysis presumes a linguistic epistemology. Within this kind of constructionist epistemology language is treated as effectively constituting or standing 
for reality (Gergen, 1997) and meaning is therefore representational in character. The patterns of language - identified as themes, discourses, positions, conversational devices or narratives - are understood to manage and represent concerns and interests in participants' lives, and their analysis as discursive, representational forms is treated as largely sufficient. There have always been some honourable exceptions to this trend: Shotter (e.g. 1993) has long argued that alongside what is spoken we must always also consider our embodied sense of [p.83] how a conversation is going, whilst Sparkes (2007) uses narrative with the explicit aim of generating embodied responses in readers. Moreover, the exclusivity once granted to language now seems to be dissipating and even some of its most determined advocates are also considering other aspects of our sociality (Gergen, 2009). Nevertheless, in psychology it still seems accurate to say that it is "the understanding of linguistic meaning within textual material" (Madill, Jordan \& Shirley, 2000, p.1) with which qualitative research is most frequently concerned

A linguistic epistemology will not suffice for research into affective phenomena, firstly because the meanings, interests and concerns they bear are not representational in character. Feelings of anger, for example, don't stand for something: rather, those feelings are part of the situation within which they arise: they don't represent (some aspect of) it, instead they co-constitute it: affect, feeling and emotion are a-representational. They are not devoid of meaning - far from it - but their meanings are immediate, arising in and of the lived moment and sensible only as elements within whatever is occurring. Their meanings derive less from what they signify or represent than from what they do: the particular ways in which they permeate, suffuse and are enfolded by aspects of the situation within which they arise.

Secondly, a linguistic epistemology will not suffice because affective phenomena consist of textures, intensities, directions, desires and valences that are known corporeally before they are identifiable linguistically. We can reflect upon or talk about them, but our reflections and descriptions are already at one remove from their occurrence. Because they are embodied, affective phenomena are always somewhat ineffable: they have a quite literally unspeakable aspect that renders them elusive to, and always slightly disjunctive with, language. The body's ineffability has long been remarked upon by philosophers, and by scholars in body studies (Shilling, 2003; Stam, 1998; B. Turner, 1984) and the affective turn simply presents one version of this enduring difficulty: 
consequently, it is something to be managed rather than resolved. We must mobilise conceptual, terminological and empirical strategies to handle the gap between what we can represent of embodied experience and what we already know of it, directly, in the immediacy of its living: but we should not imagine that the gap can simply be closed. Below, I will offer strategies to support such investigations: first considering theories and concepts, then terminology, and finally methods.

\section{Theories and Concepts}

\section{Embodied meaning}

As we have seen, qualitative research typically presumes a linguistic epistemology within which the forms, processes and categories of language all-but exhaust what can sensibly be interrogated as contributing to meaning. This stance - a basic presumption of the 'turn to language' - has generated much valuable scholarship and afforded many insights into the experiential and social aspects of health and illness. Its strengths are so great that it sometimes difficult to see how its (implicit) requirement to translate embodied states and influences into categories of and moments within language also obscures some aspects of experience. Affective qualitative health research requires an epistemological stance that can allow these embodied phenomena to become meaningful in their own right, rather than only by [p.84] refraction through the linguistic. An epistemology that might facilitate this is provided by Ruthrof (1997), who begins with accounts of meaning that locate its emergence within language (and, indeed, other symbol systems). He accepts the significance of language, and understands that differences between signs (rather than their intrinsic features) are the basis of their meaning. He also endorses poststructuralist enquiry showing how these differences are bound up with processes of cultural and historical change, recognising that the meaning of a sign is always dependent on (other, unarticulated) networks of difference, and hence always deferred. Rather than challenge this account - versions of which will be familiar to qualitative health researchers from writings on social constructionism - Ruthrof seeks to supplement and extend it. He does so with the deceptively simple proposition that embodied experience can itself be treated as a continuous flux of signs.

Simply put, Ruthrof notes that all of our experience, always, is embodied experience. Like philosophers such as Merleau-Ponty (2002) and Sheets-Johnstone (1999) he recognises that the body continuously contributes to how we understand and engage with the world, 
that its sensations and affordances are always a part of how the world appears for us. But rather than treat the body as either object or subject, or even chiasmically (in MerleauPonty's terms) as both, Ruthrof proposes that this continuous contribution to experience can itself be treated as a flow of co-occurring somatic signs. These signs are generated by multiple embodied systems which are (for example) thermal, gustatory, kinaesthetic or haptic in character. Ruthrof argues that the continuously embodied character of experience means that the linguistic signs with which qualitative health research more usually engages are always and already bound up with and suffused by these other, embodied signs, which we know as sensations or feelings. The signs of language are never separate from the signs of the body: what we speak and what we hear is always influenced by how we feel, and vice-versa: meaningful signs arise directly through and within the body, as well as through and in language.

Importantly, Ruthrof is clear that these embodied signs are not meaningful in isolation: because they are corporeal, sensual and a-representational, their meaning always has to be interpreted alongside other (typically linguistic) signs: their meaning is consequently not a-social, but neither is it simply a matter of social convention. A feeling of anxiety, for example, is already meaningful, but we also necessarily interpret this feeling immediately, in the lived moment when it arises - to render its meaning thoroughly sensible: we have forgotten something important, we don't like how someone is speaking to us, we have realised that a situation is going to be unpleasant or painful, we are mistaking a bodily sensation (e.g. hunger or trapped wind) for an emotional state, we are going to be late, we are getting ill, and so on. A feeling of anxiety is a meaningful sign, but its meaning needs to be worked up alongside the meanings of other, co-occurring signs, if we are to act upon it appropriately (and even then, of course, our interpretations may subsequently be revised).

Equally importantly, Ruthrof is also clear that embodied signs are not meaningful only because of their interpretation through other sign systems: he rejects the cognitivist claim that feelings and sensations depend solely on context for their meaning. This claim is often fallaciously supported with reference to Schacter \& Singer (1962), even though their classic experiment demonstrates only that [p.85] chemically-induced bodily arousal magnifies the affective responses generated by different kinds of social interaction, and that reports of this effect are modulated by knowledge about its causes. Rather than 
imagining that embodied signs are entirely meaningless without subsequent interpretation, Ruthrof argues that they provide corporeal textures, intensities, valences and affordances that resist some interpretations and promote others: a feeling of anxiety, for example, is not a feeling of joy, and nor is it a feeling of pain, sexual pleasure, thirst, love, nausea, fatigue or satisfaction.

In this way, Ruthrof shows that meaning is never solely linguistic. All of our experiences of the signs of language are already suffused with experiences of embodied signs, so that the two always come together. Meaning is therefore fundamentally both intersemiotic constituted from the convergence of two or more sign systems - and heterosemiotic, or heteregenous in character. Ruthrof's treatment of bodily experience as signs allows these phenomena to signify more fully as bodily signs, providing qualitative health researchers with an epistemological stance that includes embodied and affective phenomena equally alongside those of language.

\section{Embodied language}

Another conceptual resource is to be found in accounts of language that break down its distinct separation from the body, affect and feeling. Whilst there is a clear sense in which language is embodied when it is both spoken and heard, such accounts provide a more profound sense of its embodiment whilst also narrowing the gap between language and affect. Vygotsky's (1962) description of the acquisition of 'inner speech', the unverbalised commentary on our own and others' activities that strongly characterises thought, is exemplary (though see also Billig, 1987). Vygotsky proposed that there are two lines of development in humans, one biological and the other social, and these two lines come together to produce thought. The biological line of development is a maturational one, whereas the social line of development describes how inner speech has its origins in the conversations and relations to which we are exposed. Rather than arising mysteriously or spontaneously, inner speech in fact consists of truncated, 'ring-fenced' fragments of prior conversation that have been stripped free of their original context and indexicals, and which we now use to guide our actions. Vygotsky argued that when children (and adults) talk aloud to themselves - the 'egocentric' speech largely dismissed by Piaget as the product of an unsufficiently developed sense of social norms - this talking is evidence of these processes of acquisition and transformation. Elements of 
previous conversations are being taken up and converted into unspoken commentaries, and the rehearsal of these fragments aloud to oneself is a moment within these processes of acquisition and transformation.

So thought itself is partially constituted by language, which is therefore profoundly embodied. But Vygotsky was simultaneously clear that inner speech is only one aspect of thought; language "completes" thought, and the element that language completes is affective in character: "Thought itself is engendered by motivation, i.e. by our desires and needs, our interests and emotions. Behind every thought there is an affective-volitional tendency, which holds the answer to the last 'why' in the analysis of thinking." (Vygotsky 1962, p.150). Not only is language [p.86] profoundly embodied in the form of inner speech; inner speech itself is in constant interchange with elements of thought that are fundamentally affective.

In Vygotsky's account these two elements are held relatively distinct in a dualistic manner: social influence is confined largely to the line of development from conversation and interaction, and the affective is treated - by omission, if not assertion - as biological. This dualistic aspect of Vygotsky's analysis is widely recognised (van der Veer \& Valsiner, 1991) and I have argued elsewhere (Cromby, 2007) that it is unnecessarily limited because the embodied feelings that Vygotsky's account presupposes to constitute the remainder of thought are also themselves socialised. Feelings of all kinds are experienced and expressed in accord with acquired norms of using, holding and relating to the body, and in alignment with locally-obtaining 'rules' governing when, where and how emotions should be enacted, how hunger should be sated, how pain should be managed, how desires should be satisfied, how fatigue, misery, happiness, health and illness should be enacted, and so on. These normative corporeal injunctions are aligned with sociocultural assignations of (for example) gender and class (Bourdieu 1977, Young, 1990), stamped with the mores of their time and place, and overlaid and mediated by strictures and expectations communicated by parents, teachers and significant others. Thought, then, consists of (at least) two embodied and socialised streams: one of language, and one of affect and feeling. Moreover, the gap between these is constantly crossed by transformations that convert elements of inner speech into structures and habits of feeling; and, conversely, by experiences of feeling where we only subsequently seize upon 
the correct words with which to 'fix' and represent the felt experience, both to ourselves and to others.

So language is profoundly embodied as an element of thought, where it operates in continuous exchange and interpenetration with affect and feeling. Although this might seem to leave its disembodiment into books, papers and other documents intact, this apparent disembodiment is in fact superficial. Whilst it is obviously true that written words are not words in the mouths of speakers, unless these words are actually read they remain mere marks on pieces of paper: and in their reading, something interesting happens. Reading is a trivially embodied activity: it requires a brain to co-ordinate activity and process information, eyes to see, hands to hold the book, fingers to turn the page etc. But it is also profoundly embodied, in the sense that our activity of engaging with and understanding the text necessarily mobilises embodied sensations, affects and feelings. Johnson (2007) argues that even the most seemingly abstract words such as if, and, but or why are in fact indices of embodied processes of meaning-making. Following Gendlin (1997) and William James (1892), he suggests that these apparently entirely logical or rational words - seemingly content free, devoid of feeling, and meaningful only in the context of a logical sequence - are in fact markers of the sensori-motor activity within which all of our reasoning is rooted. The word 'but', for example, indexes and calls out a felt sense of obstruction to the otherwise smooth flow of a narrative or argument, an embodied sense of disjunction or blockage, a feeling of impediment or restraint. Johnson argues that other fleeting and vague embodied feelings - for example of connection, association or direction - similarly find their echo in language, and that they enable even the most seemingly disembodied, 'rational' processes of reading and thinking.[p.87]

\section{Embodied process}

Another conceptual resource that might inform qualitative analysis of affective phenomena is provided by discussions of the ontological character of affects and feelings that emphasise their location within what (Ginsburg \& Harrington, 1996) call 'situated lines of action'. Feelings and affects are purposive, dynamic, moving and, in Deleuzian terms, constitutive of becoming and change. We are always in process, always anticipating, always intending (even if we intend to stay still, do nothing). These anticipations and intentions are not only part of how we understand and interpret our own affectivity, they are constituent elements of how, from moment to moment, it gets 
configured and produced. Too often in psychology the dominance of experimentalism means that this wider realm of process, intentionality and purpose gets bracketed off as context, as if there actually were an ontologically separable individual whose appearance and activities - after the (quasi) removal of these vital constituents of human life - would somehow be both sensible, generalisable and of interest. In this pseudo-scientific logic, we find the imaginal truth of persons by pretending to strip away their societal aspects, synthetically constraining the social relations of the present moment and artificially restricting the information, choices and decisions by which participant preferences (actually, moments within socially embedded, embodied, personal-social histories) are produced. Consequently, preferences deemed irrelevant to the experiment at hand get refigured as 'individual differences' or 'error variation' and then either averaged out, or ignored: thus, as Tolman (1994) puts it, within this logic subjectivity becomes a problem, not a resource.

This approach, which institutes what Tolman (following Holzkamp) calls "a covert anthropology of the isolated, abstract individual" is common within mainstream emotion studies, which are often quantitative and experimental. Qualitative research in health psychology is already a reaction against this kind of approach, and with respect to the affective turn might therefore be located within the relational process ontology posited by Brown \& Stenner (2009). Within this ontology, becoming and process are prioritised over endurance and stability, and it is continual human activity that itself brings meaning to an ever-changing world. Objects, entities, identities and events are as thoroughly in flux as language itself, albeit that they change and move at different speeds, variable rates of acceleration. Indeed, on the human scale some aspects change so slowly and subtly that they appear all-but fixed and can be treated as such analytically: this might apply to Bourdieu's (1977) notion of habitus and its production of enduring, classed modes of embodiment, and similarly to Young's (1990) analysis of gendered styles of bodily comportment. A relational process ontology thus potentially embraces (relative) stability as well as change, whilst approaching both in a way that foregrounds their always mediated character: both the habitus (a 'structured structuring structure') and Young's gendered comportments are reproduced through and with objects, relations, discourses and practices. Thus, affects, emotions and feelings can be treated as elements of embodied process that feed into and through social interaction, chaining back to prior moments and feeding forward to constitute future opportunities. This yields an approach 
to qualitative enquiry compatible with the recognition that any instance of discourse is always simultaneously the product of prior communication and the origin of subsequent activity; that it necessarily presupposes shared [p.88] perception, shared knowledge, and shared evaluation; and that it is always suffused with affect (Brown \& Stenner 2009, p.6285; p.109-132).

\section{Terminology}

It has already been noted that definitional questions loom large within the affective turn; moreover, there is an intrinsic paradox in using words to index phenomena that are ontologically a-representational, processual, more fluid than the apparent precision of textuality seems to imply. Nevertheless, we can and do talk about affective phenomena, and if we are to research them we must adopt an appropriate terminology. Whilst both lay and academic psychologies offer relevant resources, there are some terms which are unhelpful. For example, a distinction frequently made in psychology is that between basic and secondary emotions. Basic emotions are said to be hardwired, encapsulated responses, universal to our species and capable of cultural modification only through the addition of display rules that delineate their culturally normative enactment (Ekman, 1992). Secondary emotions, by contrast, are culture specific and hence supposedly more thoroughly social. Leaving aside the various controversies surrounding notions of basic emotion - which include multiple disagreements about their number and character, empirical problems concerning their occurrence, and anthropological concerns regarding their status (Ortony \& Turner, 1990, Wierzbicka, 1999) - this distinction is unhelpful because it artificially limits the sociality of some affects. Similarly, psychology sometimes designates affective responses such as shame and embarrassment as 'social emotions' with the corresponding implication that other emotions, by contrast, are somehow less social. Such terminology pre-emptively limits the reach of social influence, working against the drive toward hybridity and co-constitution that characterises scholarship within the affective turn. Affective qualitative analyses will benefit from eschewing terminology that imports a priori settlements of the relationship between biological and social influence, instead working upon the uncertain terrain of ordinary life where the multiple significances of their continuous fluctuating and mutual interpenetrations become visible. 
Elsewhere (Cromby, 2007) I have proposed that analyses of affective phenomena might work with feelings rather than emotions or affects, since unlike the other two terms feelings are linguistic primes, universal to all cultures and languages (Shweder, 2004). Taking feelings as an analytic focus sidesteps controversies around definitions of emotion and affect, places a psychologically-appropriate emphasis on experience, foregrounds actual instances of affectivity within which the biological and the social are already bound together, may avoid the erroneous universalisation of local or culturespecific terms, and - with particular respect to language and terminology - yields a readymade palette of appropriate phrases and metaphors. These terms nevertheless need to be used with some rigour; one way of beginning to provide this is to analytically demarcate feelings as falling into three categories (for a more detailed exposition of these categories see Cromby, 2007):

\section{Emotional feelings}

Emotions are complex phenomena that implicate narrative, intentionality, appraisal, morality and identity, but all typically include a marked somatic or corporeal [p.89] component and this is what is meant by emotional feelings: the clenched gut of fear, the heavy body of sadness, the burning face of shame, and so on. Emotions have been implicated in the etiology of coronary heart and cardio-vascular disease (Everson-Rose \& Lewis, 2005; Ruiz, Hutchinson, \& Terrill, 2008), shown to impact on the workings of the immune system (Kiecolt-Glaser, McGuire, Robles, \& Glaser, 2002) and to modulate multiple pathways and dynamics relevant to disease and ill-health (Miller, Chen, \& Cole, 2009).

\section{Extra-emotional feelings}

The various embodied intensities, textures and sensations associated with urges such as hunger and thirst, states such as fatigue or illness, and experiences such as pain, being tickled or being caressed. Typically treated dismissively within the mainstream of psychology as mere sensation and thoroughly subordinated to cognition, these feelings are permeated by emotion but not reducible to it. These feelings are important here because they influence almost all health-related decisions: what, when and how much to eat and drink, whether and how much to smoke, exercise, rest, and so on; as we have seen, they are also constitutive of many symptoms, and implicated in treatment choice and concordance. 


\section{Feelings of knowing}

These are the many fleeting, subtle and vague feelings whose embodied location and character are typically difficult to convey except in terms of their relational and epistemic significance: hence we talk of feeling uncomfortable, powerless, suspicious, content and so on. In everyday interaction these feelings are characterised in English as 'gut' feelings or intuition, and they have been theorised by (Damasio, 1994) as 'somatic markers' and associated by (Johnson, 2007) with 'logical' terms such as 'and' or 'but'. As components of 'joint action' they are integral to all relations and interactions (Shotter, 1993), including interactions between doctors and patients (which may themselves have health consequences - Adler, 2002). Much work within the emergent medical humanities (e.g. Kirklin, 2010) might be understood as attempting to inculcate alternate, less instrumental, feelings of knowing amongst medical professionals.

There are rich languages associated with each of these classes of feeling. Words, phrases and metaphors that attempt to portray the somatic components of emotion appear in the scholarship of emotion studies; as synonyms in good dictionaries and thesauri; in crosscultural psychological work on emotion, and in literature and fiction. Similar resources may also be used to develop the extant language of extra-emotional feelings, augmented in some cases (e.g. pain and other symptom-like responses) with findings from appropriate medical literature. There is also already a copious language of feelings of knowing, some of which permeates psychology (e.g. feelings of threat, humiliation, empowerment, 'tip of the tongue' experiences) and some with more specific connotations: as we have seen, (Johnson, 2007) proposes that the epistemic aspects of these feelings might be captured using terms such as connection, obstruction, dissociation, direction and necessity, terms signifying the intentional quality they enact.[p.90]

Because affective phenomena are processual, affective qualitative analyses might also benefit from a language that captures something of their temporality: rather than simply nominating their character and origins, analysts might also wish to identify their temporal style. It is not just significant that someone feels, say, angry, nor that their anger is expressed openly and confrontationally rather than in a tight-lipped fashion. Analysts might also wish to explore how feelings of anger are orchestrated over time, to study the 
affective rhythms, exchanges and flows that pass within and between participants, to examine the extent to which the affects of one person are synchronised, attuned with or reactive to those of another (cf. Lewis, 1971). A terminology that might facilitate this kind of analysis appears in Stern (1985) who identifies what he calls vitality affects, dynamic, kinetic qualities of feeling distinguishable from what he calls the 'categorical' Darwinian affects of anger, joy, sadness etc. Stern describes vitality affects as "inextricably involved with all the vital processes of life, such as breathing, getting hungry, eliminating, falling asleep and emerging out of sleep, or feeling the comings and goings of emotions and thoughts" (p.54). He suggests that these qualities can be captured using terms such as surging, fading away, fleeting, explosive, crescendo, decrescendo, bursting and drawn-out. Qualitative analysts might borrow this terminology of temporal change and movement to characterise how affects and feelings are temporally enacted.

\section{Methodological procedures}

Here I will briefly describe three methodological strategies that qualitative health researchers might usefully deploy in investigation of affective phenomena: multi-modal analyses, mixed methods, and affective-textual analysis.

\section{Multi-modal analyses}

By 'multi-modal' I mean analyses using data derived from sources other than language alone. One the one hand this means that they might in principle work with any of the human senses (vision, touch, taste, smell etc.); on the other it means that they might explore meanings associated with specific places or objects (a hospital ward, a hospice, a child's first tooth, a once-vital splint) ${ }^{1}$. Compared to recordings and transcripts of interviews and focus groups such data is potentially fuller, richer, more nuanced and complex, whilst also being quite literally more situated, more 'concrete' and specific; consequently, it may have particular potential for the exploration of affect. One example of this is the use of photographs and drawings, and such analyses are already established both in health psychology (Oliffe \& Bottorff, 2007; Radley \& Taylor, 2003a), and in the investigation of embodied experience more generally (Gillies et al., 2005). They are especially suited to the investigation of affective phenomena since "the way in which we live feelings and experiences are not always available to verbal description" (Reavey \& Johnson, 2008 p.299). Images are described in health psychology as facilitating the “feeling again” of experiences (Radley \& Taylor, 2003b) and have potential to evoke - 
for both researchers and participants - felt understandings difficult to convey using words alone. Data consisting of both participant generated images and discussion of or talk about them are more thoroughly liberated from researcher-designed prompts, and their combined semiotic-discursive analysis has the potential to generate richer, more [p.91] detailed and nuanced accounts of the affective and felt aspects of health and illness. Similar advantages are likely to accrue to analyses that work along other sensory channels or mobilise significant places and treasured objects.

\section{Mixed methods}

Supplementing qualitative analyses with quantitative data is another way to include bodily and affective influence, and numerous possibilities are available. Most simply, rating scales can be used to generate crude indices of emotionality with which to characterise groups or identify individuals for more intensive qualitative analysis. Q-sorts offer a more sophisticated approach, yielding hierarchies of qualitative statements; they are well established in health psychology and have been used to study emotion and feeling (Stenner \& Stainton-Rogers, 2004). Mixed methods have also been used in health psychology in the analysis of personal projects (Vroman, Chamberlain, \& Warner, 2009), and in medical humanities in combination with images (Aita, Lydiatt \& Gilbert, 2010). Qualitative methods can also be conjoined with quantitative indices of bodily activity (galvanic skin response, heart rate, blood pressure etc.). Rather than treating these physiological measures as foundational, averaging them across groups, or conceptualising them as 'stress', they are instead used to explore how bodily activity is already bound up with the flows of social interaction. Lyons \& Cromby (2010) show how four different qualitative analytic techniques can be used alongside blood pressure data to explore the conjoined embodied-social activity of participants in conversation.

\section{Affective-textual analysis}

Affective-textual (AT) analysis borrows strategies and procedures from established qualitative methods for analysing talk and text, but adopts a process (rather than linguistic) ontology: affects, feelings and language are understood as already mutually interpenetrated and chained meaningfully together in social interaction. Cromby, Brown, Gross, Locke, \& Patterson (2010) conducted an AT analysis of the talk of community groups, using techniques borrowed from conversation analysis and discursive psychology to show how various affects (anger, wonder, disgust) helped to deploy moral categories, 
construct moral hierarchies, and enrol vulnerable groups within moral arguments. AT could complement many aspects of health psychology, including analyses of doctorpatient communication (Seymour-Smith, Wetherell, \& Phoenix, 2002), medical ethics and decision-making (Chandros-Hull, Taylor, \& Kass, 2001), and analyses of the character and consequences of narratives of health and illness (Lillrank, 2002; Williams, 2000).

\section{Conclusion}

Robertson (2001) observed that, in the human and social sciences, rather than the gradual accumulation of knowledge we most commonly have a succession of partially incommensurate mini-paradigms which arise as the dominance of one age cohort of scholars begins to fade and the next takes their place. In so doing they promote new approaches, seemingly at fundamental odds with the previous ones; consequently, instead of the progressive development of understanding we more often have its [p.92] generational churn and reconfiguration. Relatedly, Maines (2001) observes that scholars may magnify relatively small differences between their own arguments and those of previous generations in order to further their careers, but that this produces a kind of amnesia which has deleterious effects upon scholarship as a whole ${ }^{2}$.

This problem is exacerbated - if not partially produced - by the fundamentally adversarial processes of academia which, in striving to ensuring quality, coincidentally encourage scholars to adopt comprehensively defensive stances. The frequently conflictual character of peer reviews and academic debates often mean that small differences get emphasised, commonalities minimised, and the distinctions between mini-paradigms powerfully imbued (in repeated experiences of having papers rejected, funding refused, conference talks critiqued, etc.) with feelings of humiliation, pride, anger, joy, anxiety and more. These feelings get configured to stabilise, amplify and multiply difference, to impede development and continuity, to meld institutional strictures into personal imperatives in ways that become difficult to later untangle. In an academic world thoroughly imbued by the competitive logic of the capitalist market, where promotions, careers and jobs themselves, depend upon citations, research funding and influence, these structures of feeling are both adaptive and predictable - but not always conducive to scholarship, which demands co-operation and reflection as well as contest and challenge. 
Since it seems that the affective turn may represent one of these moments of change, we might sensibly heed Robertson's implicit warning and strive to ensure that its potentials do not sabotage gains already made. In social science, Hemmings (2005) has already warned that the engagement with ontology upon which affect studies are premised may generate problems, whilst Papoulias \& Callard (2010) raise concerns about borrowing from neuroscience. Within psychology, engagement with affect and feeling carries the danger, if mishandled, of a retreat to the individual, and of fostering naïve rather than critical reflexive humanisms (Parker, 1999). So there are pitfalls here, as well as potentials; the affective turn nevertheless offers exciting new possibilities for research and scholarship, with particular promise for qualitative research in health psychology.

\section{ACKNOWLEDGEMENT:}

Thanks to Antonia Lyons for her generous editorial advice regarding an earlier version of this paper.

\footnotetext{
${ }^{1}$ Thanks to both Kerry Chamberlain and one of the anonymous reviewers for emphasising the importance of these kinds of data

2 Thanks to one of the anonymous reviewers for bringing Maine's work to my attention.
}

\section{REFERENCES:}

6, P., Squire, C., Treacher, A., \& Radstone, S. (2007). Introduction. In P. 6, S. Radstone, C. Squire \& A. Treacher (Eds.), Public Emotions (pp. 1-34). London: Palgrave Macmillan.

Adler, H. (2002). The Sociophysiology of Caring in the Doctor-patient Relationship. Journal of General Internal Medicine, 17(11), 883-890.

Aita, V, Lydiatt, W. \& Gilbert, M. (2010). Portraits of Care: medical research through portraiture. Medical Humanities 36, 5-13

Athanasiou, A., Hantzaroula, P., \& Yannakopoulos, Y. (2008). Towards a New Epistemology: the "affective turn". Historein, 8, 5-16.

Ben-Ze-ev, A. (1997). Emotions and Morality. Journal of Value Inquiry, 31, 195-212.

Bendelow, G. (2009). Health, Emotion and The Body. Oxford: Polity Press.

Billig, M. (1987). Arguing and Thinking: a rhetorical approach to social psychology. Cambridge: Cambridge University Press.

Blackman, L., \& Cromby, J. (2007). Affect and Feeling. International Journal of Critical Psychology, 21, 5-22.

Blackman, L., Cromby, J., Hook, D., Papadopoulos, D., \& Walkerdine, V. (2008). Creating Subjectivities. Subjectivitiy, 22, 1-27.

Blackman, L., \& Venn, C. (2010). Affect. Body and Society, 16(1), 7-28.

Boon, H., Stewart, M., Kennard, M., Gray, R., Sawka, C., Belle-Brown, J., et al. (2000). Use of Complementary/Alternative Medicine by Breast Cancer Survivors in Ontario: Prevalence and Perceptions. Journal of Clinical Oncology, 18(13), 2515-2521. 
Bourdieu, P. (1977). Outline of a Theory of Practice (R.Nice, Trans.). Cambridge: Cambridge University Press.

Brennan, T. (2004). The Transmission of Affect. Ithaca, New York: Cornell University Press.

Brown, S. D., \& Stenner, P. (2009). Psychology Without Foundations: history, philosophy and psychosocial theory. London: Sage Publications.

Bullington, J. (2009). Embodiment and chronic pain: Implications for rehabilitation practice. Health Care Analysis, 17(2), 100-109.

Chandros-Hull, S., Taylor, H., \& Kass, N. (2001). Qualitative Methods. In J. Sugerman \& D. Sulmasy (Eds.), Methods in Medical Ethics (pp. 146-168). Washington DC: Georgetown University Press.

Clough, P. (2010). Praying and playing to the beat of a child's metronome. Subjectivity 3,4, 349-365

Clough, P., \& Halley, J. (Eds.). (2007). The Affective Turn: theorising the social. Durham NC: Duke University Press.

Costa, P., \& McCrae, R. (1987). Neuroticism, somatic complaints and disease: is the bark worse than the bite? Journal of Personality, 55, 316.

Cromby, J. (2004). Between constructionism and neuroscience: the societal coconstitution of embodied subjectivity. Theory and Psychology, 14(6), 797-821.

Cromby, J. (2007). Toward a Psychology of Feeling [Electronic Version]. International Journal of Critical Psychology, 21, 94-118 from http://wwwstaff.lboro.ac.uk/ hujc4/.

Cromby, J., Brown, S. D., Gross, H., Locke, A., \& Pattterson, A. E. (2010). Constructing Crime, Enacting morality: emotion, crime and anti-social behaviour in an inner-city community. British Journal of Criminology, 50, 873-895.

Cromby, J., \& Harper, D. (2009). Paranoia: a social account. Theory and Psychology, 19(3), 335-361.

Damasio, A. R. (1994). Descartes Error: emotion, reason and the human brain. London: Picador.

Damasio, A. R. (1999). The Feeling of What Happens: body, emotion and the making of consciousness. London: William Heinemann.

Ekman, P. (1992). Are There Basic Emotions? Psychological Review, 99(3), 550-553.

Everson-Rose, S., \& Lewis, T. (2005). Psychosocial factors and cardiovascular diseases. Annual Review of Public Health, 26, 469-500.

Ferrell, J. (2003). Tearing Down the Streets: adventures in urban anarchy. London: Palgrave Macmillan.

Gendlin, E. (1997). Experiencing and the Creation of Meaning. Evanston, Ill.: Northwestern University Press.

Gergen, K. J. (1997). Realities and Relationships: soundings in social construction. Cambridge, Mass.: Harvard University Press.

Gergen, K. J. (2009). Relational Being: beyond self and community. Oxford: Oxford University Press.

Gillies, V., Harden, A., Johnson, K., Reavey, P., Strange, V., \& Willig, C. (2005). Painting pictures of embodied experience: the use of non-linguistic data in the study of embodiment. Qualitative Research in Psychology, 2(3), 199-212.

Ginsburg, G. P., \& Harrington, M. E. (1996). Bodily states and context in situated lines of action. In R. Harre \& W. G. Parrott (Eds.), The Emotions: social, cultural and biological dimensions (pp. 229-258). London: Sage Publications. 
Greco, M., \& Stenner, P. (2008). Introduction: Emotion and Social Science. In M. Greco \& P. Stenner (Eds.), Emotions: a social science reader (pp. 1-21). London: Routledge.

Griffiths, P. (1998). What Emotions Really Are: the problem of psychological categories. Chicago: University of Chicago Press.

Hagger, M. \& Orbell, S. (2006). Illness representations and emotion in people with abnormal screening results. Psychology and Health 21,2, 183-209

Haidt, J. (2003). The Moral Emotions. In R. J. Davidson, K. Scherer \& H. Goldsmith (Eds.), Handbook of Affective Sciences (pp. 852-870). Oxford: Oxford University Press.

Hemmings, C. (2005). Invoking Affect: cultural theory and the ontological turn. Cultural Studies, 19(5), 548-567.

James, W. (1892). The Stream of Consciousness, from Psychology. Retrieved 25/01/06, 2006, from http://psychclassics.yorku.ca/James/jimmy11.htm

Jarvis, M., \& Wardle, J. (2006). Social patterning of individual health behaviours: the case of cigarette smoking. In M. Marmot \& R. G. Wilkinson (Eds.), Social Determinants of Health (pp. 224-237). Oxford: Oxford University Press.

Johnson, M. (2007). The Meaning of the Body: aesthetics of human understanding. Chicago: University of Chicago Press.

Kiecolt-Glaser, J., McGuire, L., Robles, T., \& Glaser, R. (2002). Psychoneuroimmunology: Psychological influences on immune function and health. Journal of Consulting and Clinical Psychology, 70, 537-547.

Kirklin, D. (2010) Bearing witness to people who refuse to be fragmented by illness. Medical Humanities 36,1

Lewis, H. B. (1971). Shame and guilt in neurosis. New York: International Universities Press.

Lillrank, A. (2002). The Tension between Overt Talk and Covert Emotions in Illness Narratives: Transition from Clinician to Researcher. Culture, Medicine and Psychiatry, 26(1), 111-127.

Lipton, J., \& Marbach, J. (1984). Ethnicity and the pain experience. Social Science and Medicine, 19, 1279-1298.

Lynch, J., Kaplan, G., \& Salonen, T. (1997). Why do poor people behave poorly? Variation in adult health behaviours and psychosocial characteristics by stages of the socioeconomic lifecourse. Social Science and Medicine, 44(6), 809-819.

Lyons, A., \& Chamberlain, K. (2006). Health Psychology: a critical introduction. Cambridge: Cambridge University Press.

Lyons, A., \& Cromby, J. (2010). Social Psychology and the Empirical Body: rethinking the relationship. Social and Personality Psychology Compass, 4(1), $1-13$.

Madill, A, Jordan, A \& Shirley, C 2000, 'Objectivity and reliability in qualitative analysis: realist, contextualist and radical constructionist epistemologies', British Journal of Psychology, vol. 91, pp. 1-20.

Massumi, B. (1995). The autonomy of affect. Cultural Critique, 31, 83-109.

Merleau-Ponty, M. (2002). Phenomenology of Perception (C.Smith, Trans.). London: Routledge.

Meyer, C., Waller, G., \& Waters, A. (1998). Emotional States and Bulimic Psychopathology. In H. Hock, J. Treasure \& M. Katzman (Eds.), Neurobiology in the Treatment of Nervous Disorders (pp. 271-289). London: John Wiley \& Sons Ltd. 
Middleton, D., \& Brown, S. D. (2005). The Social Psychology of Experience: studies in remembering and forgetting. London: Sage Publications.

Miller, G., Chen, E., \& Cole, S. (2009). Health psychology: Developing biologically plausible models linking the social world and physical health. Annual Review of Psychology, 60, 501-524.

Newton, T. (2003). Truly embodied sociology: marrying the social and the biological. The Sociological Review, 51(1), 20-42.

Nutbeam, B. (2000). Health literacy as a public health goal: a challenge for contemporary health education and communication strategies into the 21st century. Health Promotion International, 15(3), 259-267.

Oliffe, J., \& Bottorff, J. (2007). Further Than the Eye Can See? Photo Elicitation and Research With Men. Qualitative Health Research, 17(6), 850-858.

Ortony, A., \& Turner, J. (1990). What's basic about basic emotions? Psychological Review, 97(3), 315-331.

Pagano, S., \& Huo, Y. (2007). The Role of Moral Emotions in Predicting Support for Political Actions in Post-War Iraq. Political Psychology, 28(2), 227-255.

Paltiel, O., Avitzour, M., Peretz, T., Cherny, N., Kaduri, L., Pfeffer, R., et al. (2001). Determinants of the Use of Complementary Therapies by Patients With Cancer. Journal of Clinical Oncology, 19(9), 2439-2448.

Panksepp, J. (1998). Affective Neuroscience. Oxford: Oxford University Press.

Papoulias, C., \& Callard, F. (2010). Biology's Gift: interrogating the turn to affect. Body and Society, 16(1), 29-56.

Parker, I. (1999). Critical reflexive humanism and critical constructionist psychology. In D. J. Nightingale \& J. Cromby (Eds.), Social Constructionist Psychology: a critical analysis of theory and practice. Buckingham: Open University Press.

Ptacek, J., \& Eberhardt, T. (1996). Breaking bad news: a review of the literature. Journal of the American Medical Association, 276(6), 496-502.

Radley, A., \& Taylor, D. (2003a). Images of Recovery: A Photo-Elicitation Study on the Hospital Ward. Qualitative Health Research, 13(1), 77-99.

Radley, A., \& Taylor, D. (2003b). Remembering one's stay in hospital: a study in photography, recovery and forgetting. Health, 7, 129-159.

Ratner, C. (2000). A cultural-psychological analysis of emotions. Culture and Psychology, 6, 5-39.

Reavey, P., \& Johnson, K. (2008). Visual Approaches: using and interpreting images. In C. Willig \& W. Stainton-Rogers (Eds.), The Sage Handbook of Qualitative Research in Psychology (pp. 296-314). London: Sage Publications.

Rhudy, J., Williams, A., McCabe, K., Rambo, P., \& Russell, J. (2006). Emotional modulation of spinal nociception and pain: The impact of predictable noxious stimulation. Pain, 126(1-3), 221-233.

Robertson, A. F. (2001). Greed: gut feelings, growth and history. Cambridge: Polity Press.

Ruiz, J., Hutchinson, J., \& Terrill, A. (2008). For better and worse: Social influences on coronary heart disease risk. Social and Personality Psychology Compass, 2(3), 1400-1414.

Ruthrof, H. (1997). Semantics and the Body. Toronto: University of Toronto Press.

Schacter, S., \& Singer, J. (1962). Cognitive, social and physiological determinants of emotional state. Psychological Review, 69, 379-399.

Scheper-Hughes, N., \& Lock, M. (1987). The Mindful Body: A Prolegomenon to Future Work in Medical Anthropology. Medical Anthropology Quarterly, 1(1), 6-41. 
Scherer, K., Wranik, T., Sangsue, J., Tran, V., \& Scherer, U. (2004). Emotions in Everyday Life: probability of occurrence, risk factors, appraisal and reaction patterns. Social Science Information, 43(4), 499-570.

Sedgewick, E. (2003). Touching Feeling: affect, pedagogy, performativity. Durham: Duke University Press.

Seymour-Smith, S., Wetherell, M., \& Phoenix, A. (2002). "My wife ordered me to come!": a discursive analysis of doctors' and nurses' accounts of men's use of general practitioners. Journal of Health Psychology, 7, 253-267.

Sheets-Johnstone, M. (1999). The primacy of movement. Amsterdam: John Benjamin.

Shilling, C. (2003). The Body and Social Theory (2nd ed.). London: Sage Publications.

Shotter, J. (1993). Conversational Realities: constructing life through language. London: Sage Publications.

Shweder, R. A. (2004). Deconstructing the emotions for the sake of comparative research. In A. Manstead, N. Frijda \& A. Fischer (Eds.), Feelings and Emotions: the Amsterdam Symposium. Cambridge: Cambridge University Press.

Sointu, E. (2006). The search for wellbeing in alternative and complementary health practices. Sociology of Health and Illness, 28(3), 330-349.

Stam, H. (Ed.). (1998). The Body and Psychology. London: Sage Publications.

Stenner, P., \& Stainton-Rogers, R. (2004). Q methodology and qualiquantology: the example of discriminating between emotions. In Z. Todd, B. Nerlich, S. McKeown \& D. Clarke (Eds.), Mixing Methods in Psychology: the integration of qualitative and quantitative methods in theory and practice. Hove: Psychology Press.

Stephenson, N., \& Papadopoulos, D. (2007). Analysing Everyday Experience: social research and political change. London: Palgrave Macmillan.

Stern, D. (1985). The Interpersonal World of the Infant: a view from psychoanalysis and developmental psychology. New York: Basic Books.

Thrift, N. (2007). Non-Representational Theory: space, politics, affect. London: Routledge.

Tolman, C. (1994). Psychology, Society, Subjectivity: an introduction to German Critical Psychology. London: Routledge.

Turner, B. (1984). Body and Society. Oxford: Blackwells.

Turner, J. (2000). On the Origins of Human Emotions. Stanford, CA: Stanford University Press.

van der Veer, R., \& Valsiner, J. (1991). Understanding Vygotsky: a quest for synthesis. Oxford: Blackwells.

Vroman, K., Chamberlain, K., \& Warner, R. (2009). A Personal Projects Analysis: Examining Adaptation to Low Back Pain. Journal of Health Psychology, 14(5), 696-706.

Vygotsky, L. S. (1962). Thought and Language (E. Hanfmann \& G. Vakar, Trans.). Cambridge, Mass.: M.I.T. Press.

Watson, D., \& Pennebaker, J. (1989). Health complaints, stress and disease: exploring the central role of negative affectivity. Psychological Review, 96, 234-254.

Wierzbicka, A. (1999). Emotional Universals. Language Design, 2, 23-69.

Williams, S. (2000). Chronic illness as biographical disruption or biographical disruption as chronic illness? Reflections on a core concept. Sociology of Health and Illness, 22(1), 40-67. 
Young, I. M. (1990). "Throwing Like a Girl" and other essays in feminist philosophy and social theory. Bloomington, Indiana: Indiana University Press.

\footnotetext{
${ }^{1}$ Thanks to both Kerry Chamberlain and one of the anonymous reviewers for emphasising the importance of these kinds of data

${ }^{2}$ Thanks to one of the anonymous reviewers for bringing Maine’s work to my attention.
} 